\title{
Drug - Receptor Interactions
}

\section{Suvarna BS}

\author{
Dept of Pharmacology, \\ Melaka Manipal Medical College \\ Manipal. \\ Corresponding Author \\ Beena S Suvarna \\ Dept of Pharmacology, \\ Melaka Manipal Medical College \\ Manipal -576104 \\ Email: drbsusheel@yahoo.co.uk
}

\begin{abstract}
In present-day pharmacology and medicine, it is usually taken for granted that cells contain a host of highly specific receptors. Drugs act on the cell membrane by physical and/or chemical interactions. This is usually through specific drug receptor sites known to be located on the membrane. These are defined as proteins on or within the cell that bind with specificity to particular drugs, chemical messenger substances or hormones and mediate their effects on the body. Today, the concept of specific receptors for drugs and transmitters lies at the very heart of pharmacology. However, it is only relatively recently that the notion of drug-specific receptors has become widely accepted, with considerable doubts being expressed about their existence as late as the 1960s.
\end{abstract}

\section{KEY WORDS}

Drug, G-Protein, Interaction, PIP2, Receptor

Citation

Suvarna BS. Drug receptor intreaction. Kathmandu Univ Med J 2011;35(3):203-7.

\section{INTRODUCTION}

The drugs binding to specific sites or receptors was first discovered by Paul Ehrlich (1854-1925) while studying the interaction of dyes with biological structures which was later reviewed by Drews(2004). ${ }^{1}$ Receptor is a macromolecule or a binding site located on the surface or inside the effector cell that serves to recognise the signal molecule and initiate the response to it.

\section{HISTORICAL BACKGROUND}

Ehrlich initially believed that receptors existed only for toxins and for physiological foodstuffs and ferments. He changed his mind only in 1907, partly due to results of his own further research, but in particular also because of a different kind of receptor theory that had been proposed by the Cambridge physiologist John Newport Langley (1852-1925). ${ }^{2,3}$ Langley's concept is particularly interesting because it placed special importance on the notion of substance and of substance binding.

\section{The potential-poison theory}

Both Ehrlich and Langley had conceptualised the 'receptor' through analogy with chemical binding of substances, and their theories were viewed as 'chemical' in nature. ${ }^{2}$ Their theories got caught up in the controversy over whether pharmacological substances acted primarily through their chemical or their physical properties. The great competitor to the receptor concepts of Ehrlich and Langley was the so-called 'potential-poison' theory of the German pharmacologist Walther Straub (1874-1944). ${ }^{3}$ His research at the Stazione Zoologica in Naples involved the antagonism between atropine and the poison of the fly agaric, muscarine, on the heart of the sea snail (Aplysia) and the torpedo fish. He argued that a poison acted as long as there was a concentration difference or 'potential' between the outside and the inside of the cell. The effect was due to a deformation or other physical disturbance of the cell membrane when the poison molecules penetrated it. $^{4}$ 
Receptor theory was propounded by Alfred Joseph Clark, a theory of drug action based on occupation of receptors by specific drugs and the cellular function can be altered by interaction of the receptors with the drugs. The interaction between the drug (D) and receptor (R) is governed by the Law of action; the rate at which new DR complexes are formed is proportional to the concentration of $D$. This equation is derived from Langmuir absorption isotherm, the interaction of drug (D) with receptor (R) on forward or association rate constant ( $\mathrm{k} 1$ ) and the reverse or dissociation (k2)..$^{5}$ It has been accepted that occupation of the receptor is essential but itself not sufficient to elicit a response; the agonist must be able to induce conformational change in the receptor.

\section{BASIC SCIENCES AND METHODOLOGY}

\section{TYPES OF RECEPTORS}

Based on molecular structure and the nature of the transduction mechanism there are 4 types of receptors 6 :

1. Ligand-gated ion channels

2. G-protein-coupled receptors

3. Receptor kinases

4. Nuclear receptors

\section{Evidence for the existence of receptors ${ }^{5}$}

\section{Potency}

Potency refers to the amount of drug needed to produce a certain response and is controlled by four factors:

- Two relate to biological system containing receptors

- Two relate to interaction of drug with the receptor

Potency is often expressed as the dose of the drug that gives $50 \%$ of maximal response (ED50). The affinity (kd) of receptor for a drug is an important factor in determining the potency.

Relative potency: e.g. If $10 \mathrm{mg}$ of morphine $=100 \mathrm{mg}$ of pethidine as analgesic, morphine is 10 times more potent than pethidine.

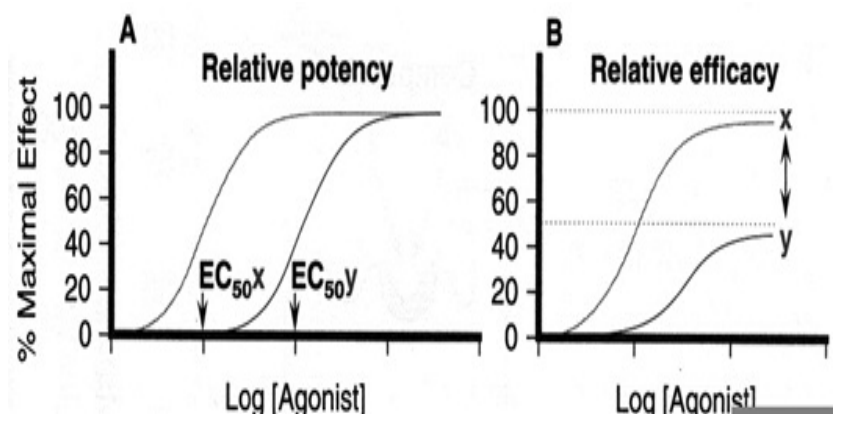

Figure 1. Relative potency and relative efficacy.

Goodmann-Gilman, McGraw-Hill Companies.

\section{Biological selectivity}

Due to increasing drugs, subtypes of receptors are now being focused along with the previously defined types. The Muscarinic receptors are being further subdivided from M1 to M5. The American pharmacologist Raymond P. Ahlquist (1914-1983) proposed the existence of two types of Adrenergic receptors, (Ahlquist 1948) alpha1 \& alpha2 and beta1, beta2, beta3. ${ }^{7}$ Similarly subtypes of receptors are now known for all hormones, transmitters, autacoids, have paved a way for the introduction of numerous clinical drugs. Receptor subtypes may be distinguished by mechanism through which their activation is linked to the response, e.g., $\mathrm{M}$ cholinergic receptors acts through G-proteins, while $\mathrm{N}$ cholinergic gates influx of $\mathrm{Na}+$ ions; alpha adrenergic receptor acts via IP3- DAG pathway and by decreasing CAMP while beta receptor increase CAMP; GABAA receptor is a ligand gated $\mathrm{Cl}$ - channel, GABAB increases $\mathrm{K}+$ conductance through $\mathrm{G}$-protein.

\section{Stereoisomerism}

Stereoisomerism can be enantiomers (have similar physicochemical properties) and diastereomers. ${ }^{8}$ e.g., dpropranolol and I- propranolol.

Binding of $d$ - propranolol to plasma albumin is more extensive than I- propranolol.

Human studies

Clinical relevance. ${ }^{8}$

a. If the study of Stereoisomerism is neglected then some important facet of clinical effects of a drug may be lost. e.g., Phenylbutazone inhibits the metabolism of Swarfarin but induces the metabolism of R- warfarin and hence the clearance of R- warfarin is unaffected.

b. Use of pure stereoisomers may improve the quality of drug by bringing specific drug action and lesser side effects and drug interaction. e.g., R- timolol used in the treatment of glaucoma may have an advantage over S-timolol as it causes less systemic beta blockade.

\section{Selective antagonism ${ }^{5}$}

Receptor antagonists are selective i.e., an AntichE will oppose the contraction of intestinal smooth muscle induced by cholinergic agonists, but not which is induced by histamine or 5-HT as they act through different receptors.

Allosteric antagonist - The drug produces its effects by binding to a site on the receptor different from that of an agonist - altering function of receptor (increase or decrease the binding and efficacy of the endogenous agonist) e.g., Benzodiazepine binds non-competitively to ion channel activated by GABA and enhances the effect of GABA channel conductance. PD 81723, an allosteric enhancer 
at the adenosine A1-receptor and thiochrome increases acetylcholine binding to the M4 muscarinic receptor. ${ }^{9,10}$

\section{Binding sites}

G-protein coupled receptor/Metabotropic represents the largest family. The human genome project has identified more than 800 different genomes; most of the drugs exert actions on only 30 of them. ${ }^{11}$ They are called G-proteins (GTP\&GDP) nucleotide.

\section{DISCUSSION}

\section{FUNCTIONS OF G-PROTEINS AND ADENYLYL CYCLASE.}

In the cell, adenylyl cyclases and G-proteins interact to catalyze the formation of adenosine 3'-5'-monophosphate (cAMP) from 5'ATP.

G-protein serves as an intermediary between hormone receptors and effector enzymes. As a result, the G-proteins aid in regulating the metabolism of molecules in response to the hormonal signals and changes. The G-protein complex consists of alpha, beta, and gamma subunits and following disassociation, the separated portions serve functional roles in the activity of the adenylyl cyclases..$^{12,13}$

A cyclase serves as an enzyme which catalyzes the cyclization of a compound. Generally, the adenylyl cyclase serves as an effector enzyme, which catalyzes 5'Adenosine Triphosphate (ATP) into cyclic Adenosine Monophosphate (cAMP). ${ }^{14}$

It is also important to note that there are nine identified isoforms of adenylyl cyclases. All of the isoforms are activated by G-alpha subunits; however some can be activated by other molecules such as forskolin or calcium ions. Each of the isoforms are characterized by distinct biochemical properties and tissue distribution throughout the body. ${ }^{15}$ For instance, adenylyl cyclase type $\mathrm{V}$ is found in the heart tissue and adenylyl cyclase type II is found in the lungs, however adenylyl cyclase type $V$ also functions as a GTPase-activating protein for G-alpha and enhances the ability of activated receptors to stimulate GTP-GDP exchange on the G-protein complex. ${ }^{16}$ They are widely spread within the membrane and hence can interact with different receptors and effectors.

GPCRs may be constitutively active in absence of any agonist. ${ }^{17}$ E.g. Histamine H3. Recent models consider G-protein receptors as dimers. ${ }^{18}$ Ergopeptide derivatives able to interact with both adenosine and dopamine receptors are developed which are important in the treatment of Parkinson's. SKF81297 and SKF83959 act on both the D1 receptor and conformation of the D2 receptor depend on the presence of the D1 receptor. SKF83959 activates a $\mathrm{Gq}$ protein; it does not activate adenylate cyclase (AC)-coupled D1 or D2 receptors or Gq/11 through D1 receptor homomeric units. Therefore, SKF83959 may be a specific agonist for $\mathrm{Gq} / 11$-coupled D1-D2 receptor hetero-oligomers. ${ }^{19}$

\section{TARGETS FOR G-PROTEINS}

\section{CAMP}

Earl Sutherland \& Ted Rall (1958) identified cyclic AMP as a key intermediate in hepatic glycogenolytic response to adrenaline \& glucagons. Studies later on identified the enzymatic activities that synthesize adenylate cyclase (AC) and degrade (cyclic nucleotide phosphodiesterase (PDE)) cAMP. ${ }^{20}$

When an agonist binds with the receptor, the G-protein activates Adenyl Cyclase which in turn activates Protein kinase (PK), Lipolysis and there is decreased glycogen synthesis with increased glycogen breakdown.

The studies on subtypes of G-protein have revealed how the receptor mediated changes in intracellular signalling can interact. For e.g., AC is regulated by $\mathrm{Gs}, \mathrm{Gi}, \mathrm{Gq}$ which affect subsets of isoenzymes of AC through the changes in the intracellular $\mathrm{Ca}_{2}{ }^{+}$and protein kinase activity. ${ }^{21}$

PDE3 \& PDE4 (cAMP selective) and PDE5 are cGMP selective. Rolipram, Milrinone are selective for PDE4; Sildenafil is selective for PDE5

\section{Phosphatidyl Inositols}

Phosphatidylinositol-4,5-bisphosphate (PIP2) is the most common doubly phosphorylated phosphoinositide in the plasma membrane of mammalian cells. ${ }^{22}$ It is a central member of the phosphoinositide pathway, and is involved in cell migration, signal transduction, actin cytoskeleton mobilization, endocytosis and exocytosis, and ion channel regulation. ${ }^{23-28}$ Hydrolysis of PIP2 by phospholipase C (PLC) yields diacylglycerol (DAG) and inositol-1,4,5-trisphosphate (IP3) that activate protein kinase $C$ (PKC) and calcium mobilization from endoplasmic reticulum (ER) stores, respectively. ${ }^{29}$ This pathway is particularly important in Purkinje cells of the cerebellum, because of its role in neuronal integration and synaptic plasticity. The major type of synaptic plasticity in the cerebellum that may underlie some forms of motor learning is long-term depression (LTD). ${ }^{30}$ Series of studies showed that Li + inhibits inositol monophosphate (IMPase) activity via an uncompetitive inhibitory mechanism. ${ }^{31}$ The Merck group developed two compounds L690, 330 and L690, 488, potent competitive inhibitors of IMPase and they resulted in agonist dependent accumulation of InsP1 to $\mathrm{Li}^{+}{ }^{32}$ Further evaluation of the drug did not proceed due to its limitation into blood brain barrier.

The key mechanism of smooth muscle contraction is Phosphorylation / dephosphorylation of ser-19 of myosin light chain II catalysed by MLCK \& MLCP (myosin light chain phosphatase). $\mathrm{Ca}^{+}$released from intracellular stores by IP3+ calmodulin thereby activating MLCK. In 2000, it was observed that same receptors could activate another 
G-protein, G12/13 to recruit monomeric GTPase, Rho to the plasma membrane. Rho-kinase can reduce blood pressure in hypertension but not normotensive rats. ${ }^{20}$

Signalling through GPCRs regulates peripheral resistance, renal function, rate and force of myocardium and cardiac hypertrophy. They respond to angiotensin II (AT1 receptors), endothelin-1 (ET1B receptors) and to alpha and beta receptors.

A Provital role for serine/threonine kinases in cardiovascular system plays an important role in cell signalling pathway. ${ }^{32}$ e.g. cardiac myocytes and vascular smooth cells.

Tyrosine Kinases ${ }^{32}$

RTKs (receptor tyrosine kinases) \& non - RTKs (Src, JAK (Janus), FAK (focal adhesion kinase)

RTKs - Epidermal growth factor, vascular endothelial growth factor and Erb-2 promote cell growth and proliferation, cell growth in cancers. Signalling through Erb-2 in cardiomyocytes protect against hypertrophic cardiomyopathy. Therefore patients on anti-Erb-2 antibodies as cancer therapy may develop cardiac dysfunction as a side effect.

GPCRs do not possess intrinsic tyrosine kinase; they activate many non-receptor tyrosine kinases to initiate their intracellular signalling programmes.

\section{Mixed kinase signals ${ }^{32}$}

Serine / threonine kinases regulate various events in CVS and they belong to a group "Mitogen activated protein kinases". The mammalian MAPKs are divided into five families: ERK1/2 (extracellular regulated kinases), p38 mapks, JNKs, ERK 3/4 and ERK5. ERKs $1 / 2$ controls cell proliferation, differentiation and survival via transcription its activation leads to myocardial hypertrophy. Calcineurin is another signalling molecule responsible for myocardial hypertrophy. Calcineurin is a calcium activated phosphatase

\section{REFERENCES}

1. Hill, S.J. G-protein-coupled receptors: past, present and future. $B$ r. J.Pharmacol 2006; 147: S27-S37.

2. Maehle A H. A binding question: the evolution of the receptor concept. Endeavour 2009; 33(4): 135-140.

3. Prüll CR. Caught between the Old and the New - Walther Straub (1874-1944), the Question of Drug Receptors, and the Rise of Modern Pharmacology. Bull Hist Med 2006 Fall; [cited on 2009 Feb 17] 80(3):465-89.Available from: http://www.ncbi.nlm.nih.gov/ pubmed/17147132]

4. Buxton, L.O. Pharmacokinetics and Pharmacodynamics: The Dynamics of drug absorption, Distribution, Action and Elimination. In: Brunton L L, Lazo J S, Parker K L, editors. Goodman \& Gilman's The Pharmacological Basis of Therapeutics; 11 th Ed. United States: McGraw-Hill Companies Inc; 2006 p 1-39.

5. Rang $\mathrm{H}$ P, Dale $\mathrm{M}$, Ritter $\mathrm{J}$ et al. How drugs act: molecular aspects. Rang and dale textbook; 6th Ed. Philadelphia: Churchill Livingston Elsevier limited, Inc; 2007 p24-53. that catalyses the dephosphorylation of NFATs (nuclear factors of activated T-cells). NFATs moves into the nucleus after dephosphorylation and interact with other transcription factors, thereby alters transcription of the hypertrophic genes. These pathways may play an important role in athletics, and in hypertrophic failing hearts. Recent evidence indicates that Calcineurin promotes the release of pro-inflammatory mediators VSMCs; suggesting Calcineurin mediated dephosphorylation events may have some pathophysiological significance in the vascular wall.

\section{CONCLUSION}

Today, we recognize a large and diverse number of physiological receptors which can be delineated into "receptor super-families" on the basis of their pharmacology and molecular properties. These receptors are now the focus of a multinational, multibillion dollar pharmaceutical industry. The receptors are not fixed elements but are subjected to regulation of receptor function. Heterodimer/ oligomers open new perspectives for GPCRs from both the functional and the pharmacological point of view.

\section{RECOMMENDATIONS}

Screening of potential drugs against heteromers of therapeutic interest, such as opioid or cannabinoid receptor heteromers for pain or dopamine/adenosine receptor heteromers for Parkinson's disease may be tried. The identification of the protein kinases and phosphatases has paved a way for the development of new drugs in the prevention of cell growth in failing hearts.

\section{THE FUTURE}

The propensity of drugs binding to different classes of receptors provides an opportunity for new developing drug molecules.

6. Ahlquist R.P. A Study of the Adrenotropic Receptors. American Journal of Physiology 1948; [cited 2009 June 14] 153:586-600. Available from http://www.ncbi.nlm.nih.gov/pubmed/18882199

7. Grahame-Smith, D.G, Aronson, J.K. The pharmacodynamic process. Is the drug producing the required ph armacological effect? Oxford Textbook of Clinical Pharmacology and Drug Therapy. 3rd Ed. Oxford: Oxford University Press, 2002 p35-46.

8. Soudijn W, Van Wijngaarden I, IJzerman AP. Allosteric modulation of $G$ protein-coupled receptors: perspectives and recent developments. Drug Discov Today 2004; 9(17):752-8.

9. Lazareno S, Dolezal V, Popham A., et al. Mol Pharmacol 2004. 65(1):257-266.

10. Wise A, Jupe S.C., Rees S. The identification of ligands at orphan G-protein coupled receptors. Ann Rev Pharmacol Toxicol 2004; [cited 2009 June 14] 44, 43-66. Available from http://www.ncbi.nlm.nih. gov/pubmed/14744238 
11. Weitmann S., Wursig N., Navarro J. M., et al. A Functional Chimera of Mammalian Guanylyl and Adenylyl Cyclases. Biochem 1999; 38 (11):3409-3413.

12. Weitmann S, Schultz G, Kleuss C: Adenylyl cyclase type II domains involved in Gbetagamma stimulation. Biochemistry 2001; 40:1085310858.

13. Parent, C., Borleis, J., Devreotes, P.N., et al. Regulation of Adenylyl Cyclases by a Region outside the Minimally Functional Cytoplasmic Domains. J Biol Chem 2001; 1354-60.

14. Onda, T., Hashimoto, Y., Nagai, M., et al. Type-specific regulation of Adenylyl Cyclase. Selective Pharmacological stimulation and inhibition of Adenylyl Cyclase isoforms. J Biol Chem 2001; 276, 47785-93.

15. Scholich, L., Mullenix, J.B., Wittpoth, C., et al. Facilitation of Signal Onset and Termination by Adenylyl Cyclase. Science 1999; 283, 132831.

16. Costa T, Cotecchia S. Historical review: negative efficacy and the constitutive activity of G-protein-coupled receptors. Trends Pharmacol Sci $2005 ; 26,616-624$

17. Franco R Casadó V, Cortés A et al. G-protein-coupled receptor heteromers: function and ligand pharmacology. B J Pharmacol 2008; 153, S90-S98

18. Rashid A J, So C, Kong $M$ et al. D1-D2 dopamine receptor heterooligomers with unique pharmacology are coupled to rapid activation of $\mathrm{Gq} / 11$ in the striatum. Proc Natl Acad Sci U S A 2007; 104(2): 654-659.

19. Nahorski R S. Pharmacology of intracellular signalling pathways. $\mathrm{Br} J$ Pharmacol 2006; 147, S38-S45

20. Cooper, D.M.F., Mons, N, Karpen, J. W. Adenylyl cyclases and the interaction between calcium and cAMP signalling. Nature 1995; 374, 421-4.

21. McLaughlin S, J Wang, A. Gambhir, and D Murray. PIP (2) and proteins: interactions, organization, and information flow. Annu Rev Biophys Biomol Struct 2002; [cited 2009 Feb 17] 31:151-175. Available from http://www.ncbi.nlm.nih.gov/pubmed/11988466

22. Sun, Y., K. Ling, M. P. Wagoner, and R. A. Anderson. Type I gamma phosphatidylinositol phosphate kinase is required for EGF-stimulated directional cell migration. J Cell Biol 2007; 178:297-308.
23. Oude Weernink P. A., M. López de Jesús, and M. Schmidt Phospholipase D signalling: orchestration by PIP2 and small GTPases. Naunyn Schmiedebergs Arch. Pharmaco/2007; [cited 2009 Feb 24] 374:399-411. Available from http://www.ncbi.nlm.nih.gov/ pubmed/17245604

24. Logan, M. R., C. A. Mandato. Regulation of the actin cytoskeleton by PIP2 in cytokinesis.2006; [cited 2009 April 14] Biol Cell 98:377-388. Available from http://www.ncbi.nlm.nih.gov/pubmed/ 16704377? Dopt $=$ Citation

25. Wenk, M. R., L. Pellegrini, V. A. Klenchin, G., et al. PIP kinase Iy is the major PI(4,5)P2 synthesizing enzyme at the synapse. Neuron 2001; [cited 2009 May 5] 32:79-88. Available from http://www.ncbi. nlm.nih.gov/ pubmed/11604140

26. Loussouarn, G., K. H. Park, C. Bellocq, et al. Phosphatidylinositol4,5-bisphosphate, PIP2, controls KCNQ1/KCNE1 voltage-gated potassium channels: a functional homology between voltage-gated and inward rectifier $\mathrm{K}^{+}$channels. EMBO J.2003; [cited 2009 Feb 17] 22:5412-21.

27. Huang, C. L., S. Feng, and D. W. Hilgemann. Direct activation of inward rectifier potassium channels by PIP2 and its stabilization by Gbetagamma. Nature 1998; [cited 2009 Feb 17] 391:803-806. Available from http://www.ncbi.nlm.nih.gov/pubmed/9486652

28. Cohen, D. Of rafts and moving water. SCi STKE 2003:e36.

29. Ito, M. Cerebellar long-term depression: characterization, signal transduction, and functional roles. Physiol Rev 2001; [cited 2009 April 19] 81:1143-95.

30. Hallcher, L.M., Sherman W.R. The effects of lithium ion and other agents on the activity of myo-inositol-I-phosphatase from bovine brain. J Biol Chem 1980; 255, 10896-10901.

31. Atack J.R., Broughton, H.B, Pollack, S.J. Inositol monophosphate - a putative target for $\mathrm{Li}+$ in the treatment of bipolar disorder. Trends Neurosci 1995; 18, 343-349.

32. Wheeler-Jones C P D. Cell signalling in the cardiovascular system: An overview. Heart 2005;91:1366-1374. 